\title{
Algoritma K-Medoids untuk Mengelompokkan Desa yang Memiliki Fasilitas Sekolah di Indonesia
}

\author{
Ivana Indriani Putri Damanik¹, Solikhun², Ilham Syahputra Saragih ${ }^{3}$, Iin Parlina4, Dedi \\ Suhendro $^{5}$, Anjar Wanto 6 \\ ${ }^{1}$ Mahasiswa Sistem Informasi STIKOM Tunas Bangsa, Pematangsiantar, Indonesia \\ 2 Dosen STIKOM Tunas Bangsa, Pematangsiantar, Indonesia \\ Jln. Jenderal Sudirman Blok A No.1/2/3 Pematangsiantar, Indonesia \\ Ivanadamanik1412@gmail.com
}

\begin{abstract}
School facilities are learning facilities and infrastructure. Study rooms, study rooms, sports halls, prayer rooms, arts rooms and sports equipment. Means of learning to read textbooks, reading books, school laboratory tools and facilities and various other learning media. This study discusses the application of the K-Medoids method in grouping villages that have school facilities based on the province and education level. Data sources used from the National Statistics Agency (BPS). This study uses data mining techniques in data processing using the $k$-medoids clustering method. The k-medoid method is part of a fairly efficient grouping of partitions in small datasets and looks for the most representative points. The advantages of this method can overcome the shortcomings of the k-means method that is sensitive to outliers. Another advantage of this method is that the results of the grouping process do not match the entry sequence of the dataset. Grouping k-medoid method can be applied to the percentage of facilities based on the province, so that provincial grouping can be determined based on the data. From the grouping data, 3 clusters were obtained, namely a low cluster of 15 provinces, a moderate cluster of 16 provinces and a high cluster of 3 provinces from the percentage of school facilities in each province. It is hoped that this research can provide information to the government about data collection of school facilities in Indonesia which discusses examiners in the provision of school facilities in Indonesia.
\end{abstract}

Keywords: School Facilities, Data Mining, K-Medoids, BPS.

\begin{abstract}
Abstrak - Fasilitas sekolah merupakan sarana dan prasarana pembelajaran. Prasarana meliputi gedung sekolah, ruang belajar, lapangan olahraga, ruang ibadah, ruang kesenian dan peralatan olahraga. Sarana pembelajaran meliputi buku pelajaran, buku bacaan, alat dan fasilitas laboratorium sekolah dan berbagai media pembelajaran lain. Penelitian ini membahas Penerapan Metode K-Medoids Dalam Pengelompokan Desa Yang Memiliki Fasilitas Sekolah Berdasarkan Provinsi dan Tingkat Pendidikan. Sumber data yang digunakan dari Badan Pusat Statistik Nasional (BPS). Penelitian ini menggunakan teknik data mining dalam proses pengolahan data dengan metode $k$-medoids clustering. Metode $k$ medoids merupakan bagian dari partitioning clustering yang cukup efisien dalam dataset yang kecil dan mencari titik yang paling representatif. Kelebihan dari metode ini mampu mengatasi kelemahan dari metode $k$-means yang sensitive terhadap outlier. Kelebihan lain dari metode ini yaitu hasil proses clustering tidak bergantung pada urutan masuk dataset. Metode k-medoids clustering dapat diterapkan pada data persentase fasilitas sekolah berdasarkan provinsi, sehingga dapat diketahui pengelompokkan provinsi berdasarkan data tersebut. Dari data pengelompokan tersebut diperoleh 3 cluster yakni cluster rendah 15 provinsi, cluster sedang 16 provinsi dan cluster tinggi 3 provinsi dari persentase fasilitas sekolah pada setiap provinsi. Diharapkan penelitian ini dapat memberikan informasi kepada pemerintah tentang pengelompokan data fasilitas sekolah di Indonesia yang berdampak pada pemerataan dalam pemberian Fasilitas sekolah di Indonesia.
\end{abstract}

Kata Kunci : Fasilitas Sekolah, Data Mining, K-Medoids, BPS. 


\section{PENDAHULUAN}

Pendidikan merupakan usaha sadar dan terencana untuk mewujudkan suasana belajar dan proses pembelajaran agar peserta didik secara aktif mengembangkan potensi dirinya [1]. Dalam mewujudkan suasana belajar yang nyaman banyak faktor yang dapat mempengaruhi, salah satunya ialah fasilitas sekolah yang lengkap dan memadai yang dapat mendorong siswa untuk secara aktif mengembangkan potensi dirinya. Tetapi banyak sekolah dibagian perdesaan provinsi Indonesia saat ini tidak memiliki fasilitas sekolah yang memadai dan layak. Berdasarkan uraian diatas banyak cabang kecerdasan buatan dalam ilmu komputer yang dapat menyelesaikan permasalahan tersebut secara kompleks diantaranya sistem pendukung keputusan, sistem pakar, data mining dan lain sebagainya. Beberapa penelitian tentang data mining Salah satunya yang dilakukan oleh Wiwit Agus Triyanto mahasiswa Sistem Informasi Universitas Muria Kudus, 2015 yang berjudul "Algoritma K-Medoids Untuk Penentuan Strategi PemasaranProduk". Metode yang digunakan dalam penelitian ini adalah K-Medoids Clustering, Menunjukan bahwa kebenaran algoritma K-Means dalam mengelompokkan penentuan strategi pemasaran produk menghasilkan 5 cluster dengan Cluster pertama terdiri dari 909 record transaksi, Cluster kedua terdiri dari 166 record transaksi, Cluster ketiga terdiri dari 66 record transaksi, Cluster keempat terdiri dari 132 record transaksi, dan Cluster kelima terdiri dari 87 record transaksi [2].

Dari beberapa penelitian tersebut data mining merupakan sebuah proses analitik yang dirancang sekian rupa untuk memeriksa sejumlah data dalam mencari suatu pengetahuan tersembunyi yang konsisten dan berharga [3]. Data mining berkaitan dengan bidang ilmu-ilmu lain, seperti database system, statistik, data warehousing, information retrieval, machine learning, dan komputasi tingkat tinggi [4]. Banyak algoritma yang terdapat didalam data mining klasifikasi salah satunya ialah $K$-Medoids. Metode $K$-Medoids adalah bagian dari partitioning clustering. Metode K-Medoids cukup efisien dalam dataset yang kecil. Langkah awal $K$-Medoids ialah mencari titik yang paling representatif (medoids) dalam dataset dengan menghitung jarak dari kelompok dalam semua kemungkinan kombinasi dari medoids sehingga jarak antar titik dalam suatu cluster kecil sedangkan jarak titik antar cluster besar [5].

\section{METODOLOGI PENELITIAN}

\subsection{Metode Penelitian}

Metode penelitian merupakan cara ilmiah dalam mencari dan mendapatkan data dengan melakukan investigasi pada data yang telah didapatkan serta memiliki kaitan dengan prosedur dalam melakukan penelitian dan teknis penelitian. Metode penelitian banyak mengulas mengenai cara dalam pelaksanaan penelitian, berbeda dengan prosedur penelitian yang lebih menekankan mengenai alat-alat yang dipakai dalam mengukur dan mengumpulkan data hasil penelitian, metode penelitian mencakup kedua hal yaitu, prosedur dan teknik penelitian. Metode pengumpulan data dilakukan untuk mendapatkan informasi data yang valid agar dapat mencapai tujuan penelitian. Metode pengumpulan data yang digunakan 
yaitu memanfaatkan buku-buku serta jurnal sebagai bahan referensi untuk mempermudah penulisan karya tulis.

\subsection{Analisis Data}

Analisis data merupakan suatu proses atau upaya pengolahan data menjadi sebuah informasi baru agar karakteristik data tersebut menjadi lebih mudah dimengerti dan berguna untuk solusi suatu permasalahan, khususnya yang berhubungan dengan penelitian. Penelitian ini menggunakan jenis data skunder. Data sekunder adalah sumber data penelitian yang diperoleh melalui media perantara atau secara tidak langsung berupa bukti yang telah ada, atau arsip baik yang dipublikasikan maupun yang tidak dipublikasikan secara umum.

\subsection{Analisa Permasalahan}

Penulis menyimpulkan dasar permasalahan dalam penelitian ini adalah jumlah fasilitas sekolah pada setiap provinsi di Indonesia masih terdapat fasilitas sekolah yang kurang layak dan tidak memadai. Untuk itu dengan adanya peningkatan fasilitas yang layak dan memadai dapat menciptakan suasana belajar yang nyaman dengan fasilitas yang lengkap dan mendorong siswa-siswi untuk secara aktif mengembangkan potensi dalam dirinya.

\subsection{Metode K-Medoids Clustering}

Metode K-Medoids adalah bagian dari partitioning clustering. Metode $K$ Medoids cukup efisien dalam dataset yang kecil. Langkah awal K-Medoids ialah mencari titik yang paling representatif (medoids) dalam dataset dengan menghitung jarak dari kelompok dalam semua kemungkinan kombinasi dari medoids sehingga jarak antar titik dalam suatu cluster kecil sedangkan jarak titik antar cluster besar [6].

\subsection{Perancangan Penelitian}

Berikut ini perancangan penelitian yang berisi diagram blokyang menjelaskan alur kerja penelitian, sebagai berikut :

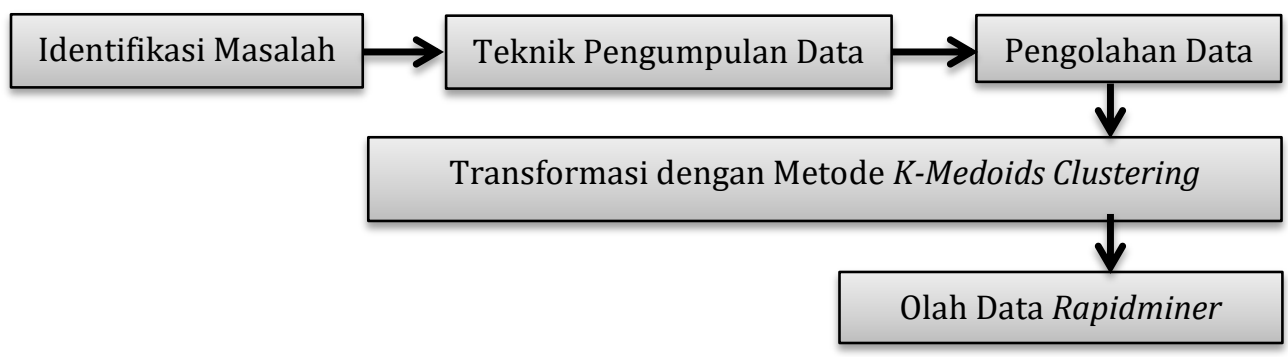

Gambar 1. Diagram Blok Alur Kerja Penelitian

\section{HASIL DAN PEMBAHASAN}

\subsection{Inisialisasi pusat cluster sebanyak dari data sampel}

Untuk pemilihan setiap medoid dipilih secara acak (random). Diasumsikan banten, sumatera utara dan papua sebagai medoid awal. 
Tabel 1. Inisialisasi Pusat Cluster Pada Medoid Awal

\begin{tabular}{|c|c|c|c|c|c|}
\hline Nama Iterasi & Keterangan & SD & SMP & SMU & SMK \\
\hline SUMUT (C2) & Diambil data ke 1 Sebagai Pusat Klaster ke 2 & 4495,6 & 1723 & 836,4 & 421,8 \\
\hline Banten (C1) & Diambil data ke 1 Sebagai Pusat Klaster ke 16 & 1502,2 & 934,8 & 455,2 & 220 \\
\hline Papua (C3) & Diambil data ke 1 Sebagai Pusat Klaster ke 34 & 1906,8 & 380 & 132,6 & 67,6 \\
\hline
\end{tabular}

\subsection{Menghitung nilai jarak terdekat (cost) dengan persamaan Euclidian Distance}

Untuk menghitung nilai jarak setiap objek dengan medoid awal dengan persamaan Euclidian Distance adalah sebagai berikut :

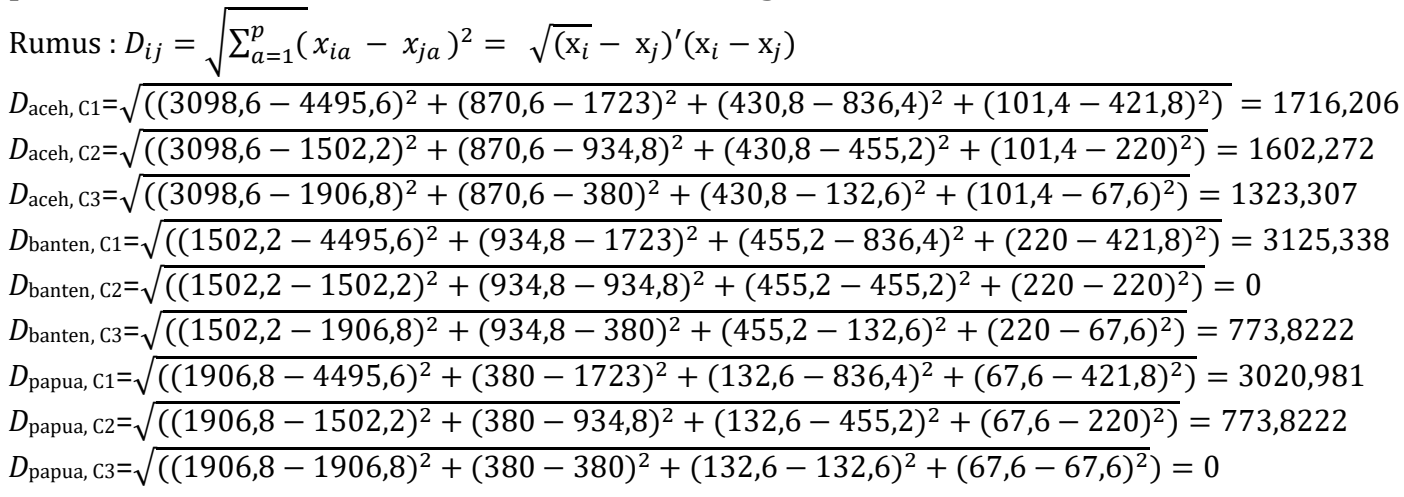

Tabel 2. Hasil Nilai Jarak (cost) Pada Iterasi Ke-1

\begin{tabular}{|c|c|c|c|c|c|}
\hline \multirow[t]{2}{*}{ Nama Provinsi } & \multicolumn{3}{|c|}{ Jarak Ke Medoid } & \multirow[t]{2}{*}{ Terdekat } & \multirow[t]{2}{*}{ Cluster yang Diikuti } \\
\hline & C1 & $\mathrm{C2}$ & C3 & & \\
\hline Aceh & 1716,206 & 1602,272 & 1323,307 & 1323,307 & 3 \\
\hline Sumatera Utara & 0 & 3125,338 & 3020,981 & 0 & 1 \\
\hline Sumatera Barat & 3812,651 & 728,1418 & 1001,497 & 728,1418 & 2 \\
\hline Riau & 3030,995 & 169,3217 & 642,7739 & 169,3217 & 2 \\
\hline Jambi & 3496,76 & 523,639 & 659,2812 & 523,639 & 2 \\
\hline Sumatera Selatan & 1976,282 & 1232,237 & 1068,941 & 1068,941 & 3 \\
\hline Bengkulu & 3764,381 & 818,8288 & 817,4056 & 817,4056 & 3 \\
\hline Lampung & 2357,078 & 778,3007 & 893,7524 & 778,3007 & 2 \\
\hline Kep. Bangka Belitung & 4527,893 & 1470,205 & 1585,342 & 1470,205 & 2 \\
\hline Kep. Riau & 4656,062 & 1585,404 & 1720,918 & 1585,404 & 2 \\
\hline Dki Jakarta & 4528,323 & 1433,029 & 1651,693 & 1433,029 & 2 \\
\hline Jawa Barat & 2211,887 & 5087,05 & 5140,504 & 2211,887 & 1 \\
\hline Jawa Tengah & 4228,508 & 7343,758 & 7203,756 & 4228,508 & 1 \\
\hline Di Yogyakarta & 4366,013 & 1281,554 & 1472,206 & 1281,554 & 2 \\
\hline Jawa Timur & 4598,009 & 7663,167 & 7615,19 & 4598,009 & 1 \\
\hline Banten & 3125,338 & 0 & 773,8222 & 0 & 2 \\
\hline Bali & 4134,124 & 1090,885 & 1211,37 & 1090,885 & 2 \\
\hline Nusa Tenggara Barat & 3771,131 & 662,246 & 1031,957 & 662,246 & 2 \\
\hline Nusa Tenggara Timur & 2038,549 & 1263,609 & 997,9742 & 997,9742 & 3 \\
\hline Kalimantan Barat & 3020,049 & 385,4085 & 414,2063 & 385,4085 & 2 \\
\hline Kalimantan Tengah & 3396,183 & 558,2527 & 497,5135 & 497,5135 & 3 \\
\hline Kalimantan Selatan & 2966,729 & 540,6514 & 262,5468 & 262,5468 & 3 \\
\hline Kalimantan Timur & 3683,218 & 666,0741 & 815,6959 & 666,0741 & 2 \\
\hline Kalimantan Utara & 4838,517 & 1774,834 & 1885,557 & 1774,834 & 2 \\
\hline Sulawesi Utara & 3427,809 & 498,9553 & 585,4493 & 498,9553 & 2 \\
\hline Sulawesi Tengah & 3170,189 & 446,8706 & 378,9913 & 378,9913 & 3 \\
\hline Sulawesi Selatan & 1643,027 & 1496,161 & 1462,229 & 1462,229 & 3 \\
\hline Sulawesi Tenggara & 3170,648 & 474,6732 & 350,0811 & 350,0811 & 3 \\
\hline
\end{tabular}




\begin{tabular}{|l|c|c|c|c|c|}
\hline \multirow{2}{*}{ Nama Provinsi } & \multicolumn{3}{|c|}{ Jarak Ke Medoid } & \multirow{2}{*}{ Terdekat } & \multirow{2}{*}{ Cluster yang Diikuti } \\
\cline { 2 - 5 } & C1 & C2 & C3 & & \\
\hline Gorontalo & 4325,577 & 1275,635 & 1389,917 & 1275,635 & 2 \\
\hline Sulawesi Barat & 4510,23 & 1448,794 & 1572,589 & 1448,794 & 2 \\
\hline Maluku & 3932,84 & 892,2662 & 1035,062 & 892,2662 & 2 \\
\hline Maluku Utara & 3942,519 & 926,0464 & 1019,037 & 926,0464 & 2 \\
\hline Papua Barat & 4424,887 & 1395,761 & 1464,033 & 1395,761 & 2 \\
\hline Papua & 3020,981 & 773,8222 & 0 & 0 & 3 \\
\hline Jumlah & 115814 & 51413,2 & 52965,6 & \\
\hline Total Cost & \multicolumn{7}{|c|}{220192,366} \\
\hline
\end{tabular}

Setelah di dapatkan hasil jarak dari setiap objek (cost) pada iterasi ke-1 maka lanjut ke iterasi ke-2. Kandidat medoid baru (non medoid) pada iterasi ke-2:

Tabel 3. Inisialisasi Pusat Cluster Pada Medoid Baru (Non-Medoid)

\begin{tabular}{|c|c|c|c|c|c|}
\hline Nama Iterasi & Keterangan & SD & SMP & SMU & SMK \\
\hline Papua (C1) & Diambil data ke 1 Sebagai Pusat Klaster ke 34 & 1906,8 & 380 & 132,6 & 67,6 \\
\hline Papua Barat (C2) & Diambil data ke 1 Sebagai Pusat Klaster ke 33 & 471 & 111 & 48,4 & 18,4 \\
\hline Jawa Timur (C3) & Diambil data ke 1 Sebagai Pusat Klaster ke 15 & 8431,6 & 3905,2 & 1698,4 & 802 \\
\hline
\end{tabular}

Hitung kembali jarak dari setiap objek pada iterasi ke-2 dengan menggunakan medoid baru

$$
\begin{aligned}
& \text { Rumus : } D_{i j}=\sqrt{\left.\sum_{a=1}^{p}\left(x_{i a}-x_{j a}\right)^{2}=\sqrt{\left(\mathrm{x}_{i}\right.}-\mathrm{x}_{j}\right)^{\prime}\left(\mathrm{x}_{i}-\mathrm{x}_{j}\right)} \\
& D_{\text {aceh, } \mathrm{C} 1}=\sqrt{\left((3098,6-471)^{2}+(870,6-111)^{2}+(430,8-48,4)^{2}+(101,4-18,4)^{2}\right)}=2763,04 \\
& D_{\text {aceh, } \mathrm{C} 2}=\sqrt{\left((3098,6-8431,6)^{2}+(870,6-3905,2)^{2}+(430,8-1698,4)^{2}+(101,4-802)^{2}\right)}=6304,549 \\
& D_{\text {aceh, } \mathrm{C} 3}=\sqrt{\left((3098,6-1906,8)^{2}+(870,6-380)^{2}+(430,8-132,6)^{2}+(101,4-67,6)^{2}\right)}=1323,307 \\
& D_{\text {banten, } \mathrm{C} 1}=\sqrt{\left((1502,2-471)^{2}+(934,8-111)^{2}+(455,2-48,4)^{2}+(220-18,4)^{2}\right)}=1395,761 \\
& D_{\text {banten, } \mathrm{C} 2}=\sqrt{\left((1502,2-8431,6)^{2}+(934,8-3905,2)^{2}+(455,2-1698,4)^{2}+(220-802)^{2}\right)}=7663,167 \\
& D_{\text {banten, } \mathrm{C} 3}=\sqrt{\left((1502,2-1906,8)^{2}+(934,8-380)^{2}+(455,2-132,6)^{2}+(220-67,6)^{2}\right)}=773,8222 \\
& D_{\text {papua, } \mathrm{C} 1}=\sqrt{\left((1906,8-471)^{2}+(380-111)^{2}+(132,6-48,4)^{2}+(67,6-18,4)^{2}\right)}=1464,033 \\
& D_{\text {papua, } \mathrm{C} 2}=\sqrt{\left((1906,8-8431,6)^{2}+(380-3905,2)^{2}+(132,6-1698,4)^{2}+(67,6-802)^{2}\right)}=7615,19 \\
& D_{\text {papua, } \mathrm{C} 3}=\sqrt{\left((1906,8-1906,8)^{2}+(380-380)^{2}+(132,6-132,6)^{2}+(67,6-67,6)^{2}\right)}=0
\end{aligned}
$$

Tabel 4. Hasil Nilai Jarak (cost) Pada Iterasi Ke-2

\begin{tabular}{|l|c|c|c|c|c|}
\hline \multirow{2}{*}{ Nama Provinsi } & \multicolumn{3}{c|}{ Jarak Ke Medoid } & \multirow{2}{*}{ Terdekat } & \multirow{2}{*}{ Cluster yang Diikuti } \\
\cline { 2 - 5 } & $\mathbf{C 1}$ & $\mathbf{C 2}$ & $\mathbf{C 3}$ & & 3 \\
\hline Aceh & 2763,04 & 6304,549 & 1323,307 & 1323,307 & 3 \\
\hline Sumatera Utara & 4424,887 & 4598,009 & 3020,981 & 3020,981 & 1 \\
\hline Sumatera Barat & 672,076 & 8374,55 & 1001,497 & 672,076 & 3 \\
\hline Riau & 1443,661 & 7583,016 & 642,7739 & 642,7739 & 3 \\
\hline Jambi & 938,4007 & 8070,1 & 659,2812 & 659,2812 & 3 \\
\hline Sumatera Selatan & 2456,229 & 6562,765 & 1068,941 & 1068,941 & 1 \\
\hline Bengkulu & 663,4899 & 8348,208 & 817,4056 & 663,4899 & 3 \\
\hline Lampung & 2101,981 & 6910,281 & 893,7524 & 893,7524 & 1 \\
\hline Kep. Bangka Belitung & 136,2694 & 9103,002 & 1585,342 & 136,2694 & 1 \\
\hline Kep. Riau & 267,6063 & 9228,67 & 1720,918 & 267,6063 & 1 \\
\hline Dki Jakarta & 335,1078 & 9089,89 & 1651,693 & 335,1078 & 2 \\
\hline Jawa Barat & 6461,724 & 2665,254 & 5140,504 & 2665,254 & 2 \\
\hline Jawa Tengah & 8635,339 & 994,3681 & 7203,756 & 994,3681 & 1 \\
\hline Di Yogyakarta & 237,1182 & 8931,829 & 1472,206 & 237,1182 & 2 \\
\hline Jawa Timur & 9005,756 & 0 & 7615,19 & 0 & 3 \\
\hline Banten & 1395,761 & 7663,167 & 773,8222 & 773,8222 & \\
\hline
\end{tabular}




\begin{tabular}{|c|c|c|c|c|c|}
\hline \multirow{2}{*}{ Nama Provinsi } & \multicolumn{3}{|c|}{ Jarak Ke Medoid } & \multirow{2}{*}{ Terdekat } & \multirow{2}{*}{ Cluster yang Diikuti } \\
\hline & C1 & C2 & C3 & & \\
\hline Bali & 305,8228 & 8710,039 & 1211,37 & 305,8228 & 1 \\
\hline Nusa Tenggara Barat & 765,3109 & 8321,119 & 1031,957 & 765,3109 & 1 \\
\hline Nusa Tenggara Timur & 2420,32 & 6623,691 & 997,9742 & 997,9742 & 3 \\
\hline Kalimantan Barat & 1413,989 & 7594,387 & 414,2063 & 414,2063 & 3 \\
\hline Kalimantan Tengah & 1033,488 & 7978,873 & 497,5135 & 497,5135 & 3 \\
\hline Kalimantan Selatan & 1467,05 & 7552,33 & 262,5468 & 262,5468 & 3 \\
\hline Kalimantan Timur & 751,6861 & 8257,358 & 815,6959 & 751,6861 & 1 \\
\hline Kalimantan Utara & 421,7626 & 9413,685 & 1885,557 & 421,7626 & 1 \\
\hline Sulawesi Utara & 1003,495 & 8003,869 & 585,4493 & 585,4493 & 3 \\
\hline Sulawesi Tengah & 1259,615 & 7750,549 & 378,9913 & 378,9913 & 3 \\
\hline Sulawesi Selatan & 2802,27 & 6204,755 & 1462,229 & 1462,229 & 3 \\
\hline Sulawesi Tenggara & 1257,881 & 7754,242 & 350,0811 & 350,0811 & 3 \\
\hline Gorontalo & 140,2314 & 8899,907 & 1389,917 & 140,2314 & 1 \\
\hline Sulawesi Barat & 137,5179 & 9083,927 & 1572,589 & 137,5179 & 1 \\
\hline Maluku & 508,758 & 8505,741 & 1035,062 & 508,758 & 1 \\
\hline Maluku Utara & 486,2441 & 8520,375 & 1019,037 & 486,2441 & 1 \\
\hline Papua Barat & 0 & 9005,756 & 1464,033 & 0 & 1 \\
\hline Papua & 1464,033 & 7615,19 & 0 & 0 & 3 \\
\hline Jumlah & 59577,9 & 250223,5 & 52965,6 & & \\
\hline Total Cost & & 62766,951 & & & \\
\hline
\end{tabular}

\subsection{Hitung Total Simpangan (S)}

Setelah didapatkan nilai jarak antara iterasi ke-1 dan iterasi ke-2, hitung total simpangan (S) dengan mencari selisih dari nilai total cost baru - nilai total cost lama. Dengan ketentuan jika $\mathrm{S}<0$, maka tukar nilai objek dengan menentukan medoid baru.

$\mathrm{S}=$ Total cost baru - Total cost lama

$$
\begin{aligned}
& =362766,9519-220192,366 \\
& =142574,5859
\end{aligned}
$$

Karena nilai $S>0$ maka proses cluster dihentikan. Sehingga diperoleh anggota tiap clusterpada tabel 4.5 sebagai berikut :

Tabel 5. Hasil Pengklasteran Dengan K-Medoids Clustering

\begin{tabular}{|l|c|c|c|c|c|}
\hline \multirow{2}{*}{ Nama Provinsi } & \multicolumn{3}{|c|}{ Jarak Ke Medoid } & \multirow{2}{*}{ Terdekat } & $\begin{array}{c}\text { Cluster yang } \\
\text { Diikuti }\end{array}$ \\
\cline { 2 - 5 } & C1 & C2 & C3 & 1323,30695 & 1 \\
\hline Aceh & 1323,3069 & 2763,040477 & 6304,5489 & 1323,3065 & 1 \\
\hline Sumatera Utara & 3020,9811 & 4424,886973 & 4598,0092 & 3020,98105 & 2 \\
\hline Sumatera Barat & 1001,4975 & 672,0759778 & 8374,5499 & 672,075978 & 1 \\
\hline Riau & 642,77393 & 1443,660694 & 7583,0157 & 642,773926 & 1 \\
\hline Jambi & 659,28124 & 938,4006667 & 8070,1001 & 659,281245 & 1 \\
\hline Sumatera Selatan & 1068,9405 & 2456,229256 & 6562,7649 & 1068,9405 & 2 \\
\hline Bengkulu & 817,40558 & 663,4898643 & 8348,2081 & 663,489864 & 1 \\
\hline Lampung & 893,75245 & 2101,980637 & 6910,2814 & 893,752449 & 2 \\
\hline Kep. Bangka Belitung & 1585,342 & 136,269439 & 9103,002 & 136,269439 & 2 \\
\hline Kep. Riau & 1720,918 & 267,606278 & 9228,6701 & 267,606278 & 2 \\
\hline Dki Jakarta & 1651,6927 & 335,1078035 & 9089,8902 & 335,107804 & 3 \\
\hline Jawa Barat & 5140,5043 & 6461,723748 & 2665,2538 & 2665,2538 & 3 \\
\hline Jawa Tengah & 7203,756 & 8635,338752 & 994,3681 & 994,368101 & 2 \\
\hline Di Yogyakarta & 1472,2058 & 237,1181984 & 8931,829 & 237,118198 & 2 \\
\hline Jawa Timur & 7615,1903 & 9005,755657 & 0 & 0 & 3 \\
\hline
\end{tabular}




\begin{tabular}{|l|c|c|c|c|c|}
\hline \multirow{2}{*}{ Nama Provinsi } & \multicolumn{3}{|c|}{ Jarak Ke Medoid } & \multirow{2}{*}{ Terdekat } & $\begin{array}{c}\text { Cluster yang } \\
\text { Diikuti }\end{array}$ \\
\cline { 2 - 5 } & C1 & C2 & C3 & & 1 \\
\hline Banten & 773,82215 & 1395,760968 & 7663,1671 & 773,82215 & 2 \\
\hline Bali & 1211,3701 & 305,8228245 & 8710,0388 & 305,822825 & 2 \\
\hline Nusa Tenggara Barat & 1031,9573 & 765,3108911 & 8321,1194 & 765,310891 & 1 \\
\hline Nusa Tenggara Timur & 997,97421 & 2420,320028 & 6623,6908 & 997,974208 & 1 \\
\hline Kalimantan Barat & 414,20628 & 1413,98925 & 7594,3874 & 414,206277 & 1 \\
\hline Kalimantan Tengah & 497,51354 & 1033,487881 & 7978,8726 & 497,513538 & 2 \\
\hline Kalimantan Selatan & 262,54676 & 1467,049515 & 7552,3299 & 262,546758 & 2 \\
\hline Kalimantan Timur & 815,69595 & 751,6860515 & 8257,3576 & 751,686051 & 1 \\
\hline Kalimantan Utara & 1885,5567 & 421,7626347 & 9413,6853 & 421,762635 & 1 \\
\hline Sulawesi Utara & 585,44933 & 1003,495092 & 8003,8692 & 585,449332 & 1 \\
\hline Sulawesi Tengah & 378,99135 & 1259,615338 & 7750,5487 & 378,991346 & 1 \\
\hline Sulawesi Selatan & 1462,2292 & 2802,270458 & 6204,7546 & 1462,22923 & 2 \\
\hline Sulawesi Tenggara & 350,08113 & 1257,880932 & 7754,2423 & 350,081133 & 2 \\
\hline Gorontalo & 1389,9168 & 140,2313802 & 8899,9068 & 140,23138 & 2 \\
\hline Sulawesi Barat & 1572,5886 & 137,5178534 & 9083,9272 & 137,517853 & 2 \\
\hline Maluku & 1035,0617 & 508,7580171 & 8505,741 & 508,758017 & 2 \\
\hline Maluku Utara & 1019,0372 & 486,2441362 & 8520,3752 & 486,244136 & 2 \\
\hline Papua Barat & 1464,0331 & 0 & 9005,7557 & 0 & 2 \\
\hline Papua & 0 & 1464,033101 & 7615,1903 & 0 & 1 \\
\hline
\end{tabular}

Berdasarkan penjelasan diatas mengenai penggunaan serta hasil yang telah ditampilkan, maka pembahasan ini mengenai keterkaitan dari hasil yang di peroleh antara perhitungan algoritma dengan hasil pengujian pada tools Rapidminer 5.3.

\subsection{Validasi Data}

Dalam melakukan validasi data perhitungan algoritma harus menghasilkan hasil akhir berupa pengelompokkan dengan 3 cluster, serta data yang digunakan merupakan data yang valid dan sama dengan yang dipakai pada tools Rapidminer 5.3. Berikut ditampilkan hasil yang didapatkan dari perhitungan algoritma dan pengujian pada rapidminer 5.3 .

Tabel 6. Perbandingan Hasil Akhir K-Medoids

\begin{tabular}{|l|c|c|}
\hline \multicolumn{1}{|c|}{ Provinsi } & Perhitungan Algoritma K-Medoids & Pengujian Dengan Rapidminer 5.3 \\
\hline Aceh & Cluster_1 & Cluster_0 \\
\hline Sumatera Utara & Cluster_1 & Cluster_0 \\
\hline Sumatera Barat & Cluster_2 & Cluster_1 \\
\hline Riau & Cluster_1 & Cluster_0 \\
\hline Jambi & Cluster_1 & Cluster_0 \\
\hline Sumatera Selatan & Cluster_1 & Cluster_0 \\
\hline Bengkulu & Cluster_2 & Cluster_1 \\
\hline Lampung & Cluster_1 & Cluster_0 \\
\hline Kep. Bangka Belitung & Cluster_2 & Cluster_1 \\
\hline Kep. Riau & Cluster_2 & Cluster_1 \\
\hline Dki Jakarta & Cluster_2 & Cluster_1 \\
\hline Jawa Barat & Cluster_3 & Cluster_2 \\
\hline Jawa Tengah & Cluster_3 & Cluster_2 \\
\hline Di Yogyakarta & Cluster_2 & Cluster_1 \\
\hline Jawa Timur & Cluster_3 & Cluster_2 \\
\hline Banten & Cluster_1 & Cluster_0 \\
\hline Bali & Cluster_2 & Cluster_1
\end{tabular}




\begin{tabular}{|l|c|c|}
\hline \multicolumn{1}{|c|}{ Provinsi } & Perhitungan Algoritma K-Medoids & Pengujian Dengan Rapidminer 5.3 \\
\hline Nusa Tenggara Barat & Cluster_2 & Cluster_1 \\
\hline Nusa Tenggara Timur & Cluster_1 & Cluster_0 \\
\hline Kalimantan Barat & Cluster_1 & Cluster_0 \\
\hline Kalimantan Tengah & Cluster_1 & Cluster_0 \\
\hline Kalimantan Selatan & Cluster_1 & Cluster_0 \\
\hline Kalimantan Timur & Cluster_2 & Cluster_1 \\
\hline Kalimantan Utara & Cluster_2 & Cluster_1 \\
\hline Sulawesi Utara & Cluster_1 & Cluster_0 \\
\hline Sulawesi Tengah & Cluster_1 & Cluster_0 \\
\hline Sulawesi Selatan & Cluster_1 & Cluster_0 \\
\hline Sulawesi Tenggara & Cluster_1 & Cluster_0 \\
\hline Gorontalo & Cluster_2 & Cluster_1 \\
\hline Sulawesi Barat & Cluster_2 & Cluster_1 \\
\hline Maluku & Cluster_2 & Cluster_1 \\
\hline Maluku Utara & Cluster_2 & Cluster_1 \\
\hline Papua Barat & Cluster_2 & Cluster_1 \\
\hline Papua & Cluster_1 & Cluster_0 \\
\hline
\end{tabular}

\section{KESIMPULAN}

Penerapan data mining menggunakan metode $k$-medoids pada data fasilitas sekolah tahun 2003, 2005, 2011, dan 2014 dapat diterapkan. Data bersumber dari Badan Pusat Statistik Nasional.Jumlah record yang digunakan dalam perhitungan sebanyak 34 provinsi menghasilkan 3 cluster yakni 3 provinsi sebagai cluster tertinggi, 16 provinsi sebagai cluster sedang dan 15 provinsi sebagai cluster terendah. Berdasarkan implementasi menggunakan tools rapidmine r5.3 diperoleh hasil yang sama antara perhitungan manual dengan pengujian menggunakan sistem dimana cluster rendah dapat menjadi masukkan kepada pihak pemerintah agar lebih memperhatikan provinsi dengan jumlah fasilitas sekolah yang rendah.

\section{DAFTAR PUSTAKA}

[1] Riyadus Solihin and Achmad Ryan Fauzi, "Penurunan Minat bersekolah di SD Negeri dibandingkan SD Islam," Briliant J. Ris. dan Konseptual, vol. 2, no. 3, pp. 392-401, 2017.

[2] W. A. Triyanto, "Algoritma K-Medoids Untuk Penentuan Strategi Pemasaran," Simetris, vol. 6, no. 1, pp. 183-188, 2015.

[3] D. F. Pramesti, M. T. Furqon, and C. Dewi, "Implementasi Metode K-Medoids Clustering Untuk Pengelompokan Data Potensi Kebakaran Hutan / Lahan Berdasarkan Persebaran Titik Panas ( Hotspot )," J-ptiik, vol. 1, no. 9, pp. 723-732, 2017.

[4] S. Defiyanti and M. Jajuli, "Optimalisasi K - Medoid Dalam Pengklasteran Mahasiswa Pelamar Beasiswa Dengan Cubic Clustering Criterion,” TEKNOSI, vol. 03, no. 01, pp. 211-218, 2017.

[5] H. Zayuka, S. M. Nasution, Y. Purwanto, F. T. Elektro, and U. Telkom, "Perancangan Dan Analisis Clustering Data Menggunakan Metode K-Medoids Untuk Berita Berbahasa Inggris Design and Analysis of Data Clustering Using K-Medoids Method," e-Proceeding Eng. , vol. 4, no. 2, pp. 2182-2190, 2017.

[6] H. Zayuka, S. M. Nasution, and Y. Purwanto, "Perancangan Dan Analisis Clustering Data Menggunakan Metode K-Medoids Untuk Berita Berbahasa Inggris Design and Analysis of Data Clustering Using K-Medoids Method For English News," e-Proceeding Eng. , vol. 4, no. 2, pp. 2182-2190, 2017. 